\title{
Dormancy in breast cancer
}

This article was published in the following Dove Press journal:

Breast Cancer:Targets and Therapy

4 December 2012

Number of times this article has been viewed

\author{
Malgorzata Banys 1,2 \\ Andreas D Hartkopf' \\ Natalia Krawczyk' \\ Tatjana Kaiser' \\ Franziska Meier-Stiegen' \\ Tanja Fehm' \\ Hans Neubauer' \\ 'Department of Obstetrics and \\ Gynecology, University of Tuebingen, \\ Tuebingen, Germany; ${ }^{2}$ Department \\ of Obstetrics and Gynecology, \\ Marienkrankenhaus Hamburg, \\ Hamburg, Germany
}

\begin{abstract}
Tumor dormancy describes a prolonged quiescent state in which tumor cells are present, but disease progression is not yet clinically apparent. Breast cancer is especially known for long asymptomatic periods, up to 25 years, with no evidence of the disease, followed by a relapse. Factors that determine the cell's decision to enter a dormant state and that control its duration remain unclear. In recent years, considerable progress has been made in understanding how tumor cells circulating in the blood interact and extravasate into secondary sites and which factors might determine whether these cells survive, remain dormant, or become macrometastases. The mechanisms of tumor cell dormancy are still not clear. Two different hypotheses are currently discussed: tumor cells persist either by completely withdrawing from the cell cycle or by continuing to proliferate at a slow rate that is counterbalanced by cell death. Because dormant disseminated tumor cells may be the founders of metastasis, one hypothesis is that dormant tumor cells, or at least a fraction of them, share stem cell-like characteristics that may be responsible for their long half-lives and their suggested resistance to standard chemotherapy. Therefore, knowledge of the biology of tumor cell dormancy may be the basis from which to develop innovative targeted therapies to control or eliminate this tumor cell fraction. In this review, we discuss biological mechanisms and clinical implications of tumor dormancy in breast cancer patients.
\end{abstract}

Keywords: tumor dormancy, disseminated tumor cell, circulating tumor cell, targeted therapy

\section{Introduction}

The theory of hematogenous spread of solid malignancies and its role in metastasis development was originated by several researchers in the 19 th century. ${ }^{1}$ In breast cancer, the presence of single disseminated tumor cells (DTC) in bone marrow is a common phenomenon, observed in up to $40 \%$ of patients at primary diagnosis. ${ }^{2}$ Therefore, DTC detection is increasingly regarded as a clinically relevant prognostic factor for breast cancer; a pooled analysis of bone marrow samples from more than 4,700 patients revealed that their presence is correlated with a poor outcome. ${ }^{2}$ Further, DTC are able to survive chemotherapy, and their persistence is a strongly negative prognostic factor. ${ }^{3,4}$ Beyond detection in bone marrow, single tumor cells are frequently encountered in peripheral blood. These circulating tumor cells (CTC) are routinely found, depending on stage of the disease and detection method, in $10 \%$ to $80 \%$ of breast cancer patients. Conclusive data on the clinical relevance of CTC are pending; nevertheless, recent studies have shown a prognostic potential of CTC in both primary and metastatic settings. 5,6
Department of Obstetrics and

Gynecology, University of Tuebingen,

Calwerstrasse 7, 72076 Tuebingen,

Germany

Tel +49 707 I298 22 I]

Fax +49707 I294663

Email tanja.fehm@t-online.de 
Every day, large numbers of tumor cells are shed into the circulation of cancer patients. ${ }^{78}$ Many of these CTC are already apoptotic or dead; less than $0.1 \%$ will give rise to secondary growth. ${ }^{9}, 10$ Most of the still-viable CTC are supposed to be eliminated in the bloodstream by shear forces or simply by neglect, as they have lost vital contact with stromal cells supporting primary tumors. ${ }^{7,11,12}$ This phenomenon, described as "metastatic inefficiency," is consistent with the observation that detection of tumor cells in blood or bone marrow does not inevitably predict metastasis; 50\% of initially DTC-positive patients stay disease-free and do not experience a relapse. ${ }^{2}$ Studies suggest that $0.01 \%$ of CTC can ultimately produce a single bone metastasis, and at least 10,000 CTC are required for the development of a metastatic colony. ${ }^{13,14}$ Nonetheless, approximately one-third of patients fail to clear tumor cells from the blood following removal of primary tumor. ${ }^{15,16}$ Only a small fraction of CTC may be viable and able to enter secondary sites by mechanical entrapment or active migration through the endothelial cell layer. ${ }^{17-20}$ Factors supporting extravasation are highly heterogeneous, including platelets; leucocytes; macrophages and factors secreted by them; selectins and their ligands expressed on endothelial cells and tumor cells, respectively; integrins; and fibrin deposition. ${ }^{17}$

Our picture of the colonization of secondary sites by tumor cells has developed from the "seed and soil" hypothesis developed in 1889 by Paget, emphasizing the interactions between cancer cells and the microenvironment of secondary homing sites. ${ }^{21}$ However, whether tumor cells have developed a tropism for a certain secondary organ or whether tumor cells are seeded as DTC throughout the body but grow only in certain organs has not yet been finally solved. Recently, the concept of the premetastatic niche - a microenvironment permissive to the development of metastases - has gained much interest. ${ }^{22}$ It has been shown that DTC preferentially localize to these sites. ${ }^{23,24}$ Interestingly, the primary tumor itself appears to determine in which organs premetastatic niches will form by secreting soluble factors, such as vascular endothelial growth factor (VEGF)-A and placenta growth factor; in this way, the primary tumor will finally determine the distribution of metastases in the body. ${ }^{23} \mathrm{~A}$ further component of the premetastatic niche seems to be fibronectin, which may assist in recruitment of bone marrow cells. ${ }^{25}$

Although DTC, as stated above, can be found in a high percentage of breast cancer patients, and although they are relevant to prognosis, not all patients with DTC develop metastases or a relapse. This suggests that a significant proportion of tumor cells in secondary sites are in a dormant state. Figure 1 shows the possible fates of CTC and DTC.

\section{Cancer dormancy}

The phenomenon of tumor dormancy has long been recognized clinically; this term describes a prolonged quiescent state in which tumor cells are present, but disease progression is not clinically apparent. Breast cancer is especially known for long asymptomatic periods - up to 25 years - with no evidence of the disease, followed by a relapse. ${ }^{26,27}$ After this interval, the mortality rate is comparable to that of the general population..$^{28}$ Tumor dormancy has also been observed in renal, prostate, and thyroid cancers, as well as in melanoma and B-cell lymphoma, whereas late recurrences are rare in lung and colon cancers. Based on autopsy studies conducted to analyze the metastatic spread of human cancers, Rupert Willis coined the term "dormant tumor cells." ${ }^{29}$ Little is known regarding the mechanisms underlying this state, and - despite the clinical importance of tumor dormancy - the biology of dormant cells is poorly understood.

Meng et al detected CTC in 36\% of breast cancer patients who showed no evidence of the disease for 7 years or more after treatment. A major fraction of patients with dormant CTC will not experience a relapse during their lifetimes..$^{30}$ CTC were able to persist in breast cancer patients for as long as 22 years; however, their tumorigenic potential seems limited. Breast cancer patients with tumor cell dormancy present with an apparent balance between replication and cell death. Interestingly, similar findings were reported for murine B-cell leukemia 1 lymphoma. Based on animal models, Holmgren et al suggested that angiogenesis suppression could result in such a balance. ${ }^{31}$ Dormant tumor cells appear to be quite stable. In prostate cancer patients who had no evidence of disease, the proportion of patients with dormant DTC in their bone marrow less than 1 year after surgery was $64 \%$; this proportion remained similarly high $1-5$ years postsurgery (63\%) and fell only slightly to $45 \%$ more than 5 years after surgery. ${ }^{32}$ In animal models, the viability of dormant tumor cells was found to be more than 6 months. ${ }^{33}$

Many hypotheses have been developed to explain the cellular homeostasis observed in cancer dormancy by mechanisms such as insufficient angiogenesis, an effective immune response that keeps the carcinoma population stable at low levels, or cross-talk with cells or proteins released in the microenvironment arresting cancer cells in $\mathrm{G} 0-1$. Dormant tumor cells may persist in a quiescent state for many years as single cells that are resistant to therapies that eradicate 


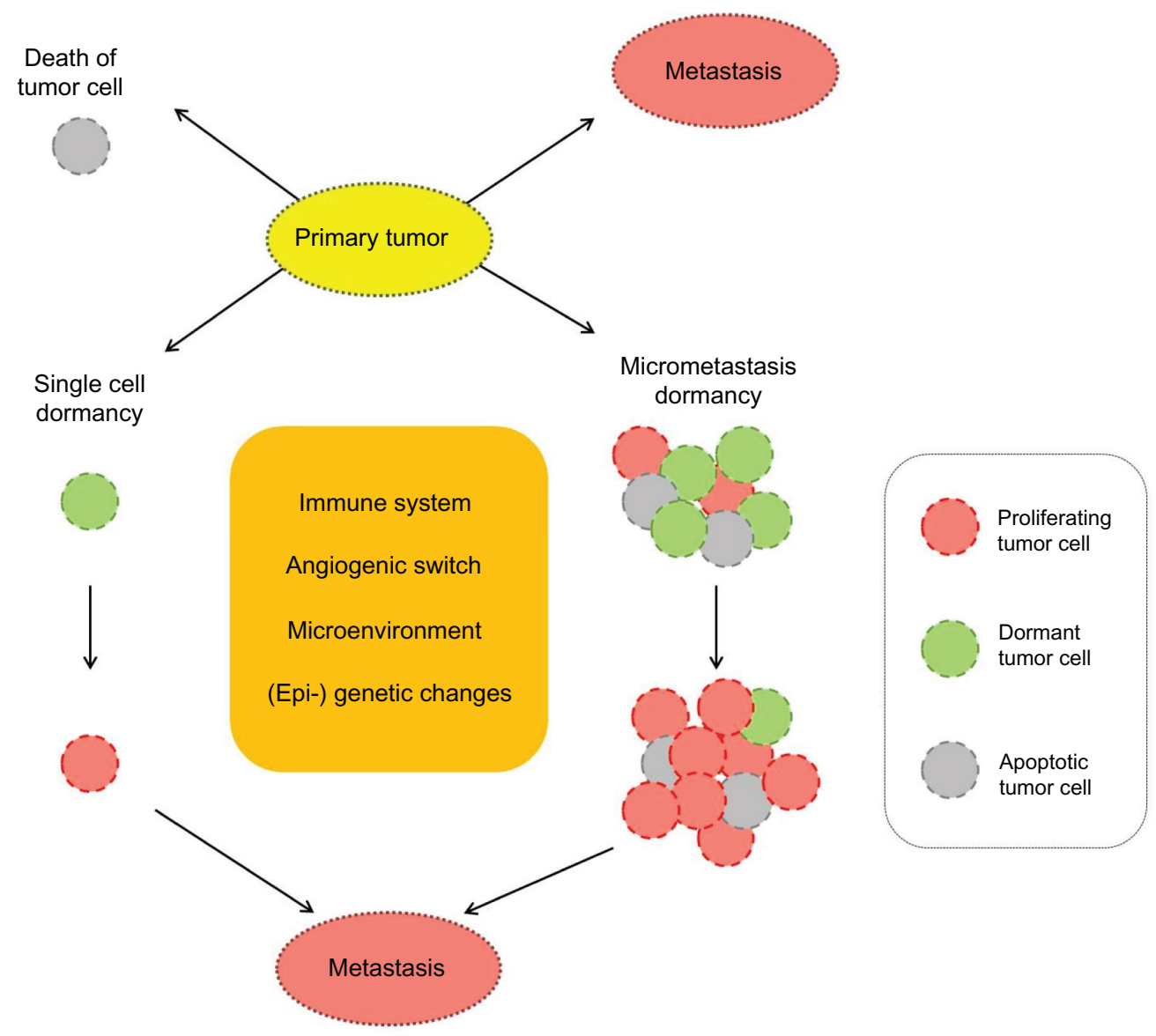

Figure I Possible fates of tumor cells detached from primary tumor.

Notes: Tumor cells disseminate at a secondary site and are subject to one of three possible fates: the tumor cells can proliferate aggressively, resulting in early metastasis; undergo apoptosis and die; or remain dormant. Two hypothetical models of tumor dormancy in breast cancer can occur: (I) In the single-cell dormancy model (left), cells derived from primary tumor remain quiescent in a state of G0-I mitotic arrest at a secondary site and may be reactivated by genetic changes or by an altered microenvironment. (2) In the micrometastatic dormancy model (right), tumor cells proliferate and continue to form micrometastases at secondary homing sites. The micrometastases have a balanced state of proliferation and apoptosis; their growth is regulated by angiogenic and immunological factors within the microenvironment.

proliferating cells. ${ }^{34,35}$ Meng et al performed a comprehensive analysis of the half-life of circulating tumor cells in patients whose primary tumor had just been removed and concluded that the half-life is very short (estimated $1-2.4$ hours). ${ }^{30}$ This is consistent with previous findings that epithelial cells separated from the stroma and neighboring cells enter an apoptotic program. ${ }^{36}$ As the half-life of CTC is measured in hours and many of the detected cells are apoptotic, it might be hypothesized that a source of replicating tumor cells at secondary homing sites is necessary to constantly replenish the CTC and keep them at the same low level for many years. ${ }^{30}$ The number of persisting tumor cells might be kept in balance by a tight regulation of proliferation and cell death. This could be accomplished by asymmetric cell division, which gives rise to a similar undifferentiated daughter cell responsible for propagation of DTC and another daughter cell replenishing the CTC pool or eventually undergoing cell death. This is a scenario that has been suggested for adult stem cells, further supporting the idea that DTC generating metastases might have a stem cell-like phenotype.

\section{Potential mechanisms of tumor cell dormancy}

Factors that determine the length of the dormancy period remain unclear. ${ }^{37}$ Current data have led to various experimental models that address the phenomenon of tumor dormancy. It appears that dormant cancer cells can persist either by completely withdrawing from the cell cycle (mitotic arrest) or by continuing to proliferate at a slow rate that is counterbalanced by cell death (Figure 1). ${ }^{38,39}$ These two types of dormancy are not mutually exclusive; both forms of latency could coexist in the entire population of DTC of a particular cancer patient.

\section{Single-cell dormancy}

In the single-cell dormancy model, isolated tumor cells detached from the primary tumor arrive at the future 
metastatic organ and enter a prolonged state of mitotic arrest. This model of arrested apoptosis contrasts with the micrometastatic dormancy model, in which proliferation in micrometastatic foci is counterbalanced by cell death. Speculations about the metabolic status of minimal residual disease (MRD) during dormancy are not yet sufficiently investigated. Cell cycle regulation mechanisms are highly complex, with various stimuli interacting at numerous cell cycle checkpoints to determine the proliferative status. The presence of tumor cell dormancy due to a growth arrest of cancer cells is supported by evidence that within tissues where primary tumors are developing or tissues that harbor disseminated cells and have a functional vasculature, tumor cells are found to be in a nonproliferative mode. ${ }^{40-42}$ In several studies, dormant cancer cells have been demonstrated to be in a G0-1 arrest; this was linked to negative staining for proliferation markers (eg, Ki67, PCNA). ${ }^{43,44}$ Dormant tumor cells may gain a survival advantage by blocking the receptors for tumor necrosis factor-related apoptosis-inducing ligand (TRAIL), which would result in arrested apoptosis. Two exemplary mechanisms of TRAIL-receptor blocking have been described and may be of relevance to dormant tumor cells. TRAIL receptors in cancer cells can be blocked by osteoprotegerin, an important member of the tumor necrosis factor receptor superfamily. ${ }^{45,46}$ Interestingly, bone marrow stromal cells from breast cancer patients secrete enough osteoprotegerin to inhibit apoptosis in vitro. ${ }^{47}$ More recently, c-Src (a tyrosin-specific kinase involved in breast cancer progression) was demonstrated to support cancer cell survival in the bone marrow microenvironment by conferring resistance to TRAIL. ${ }^{48}$

\section{Micrometastatic dormancy}

In contrast to dormancy due to mitotic arrest, dormancy of a micrometastasis seems to be caused by a balance of cell proliferation and apoptosis, such that the tumor does not increase in size. This constant balance is regulated by proangiogenic proteins and angiogenic inhibitors produced by tumor and stromal cells, as well as immunologic, hormonal, or other microenvironmental switches. ${ }^{49}$ According to Naumov et al, a failure to activate the angiogenic switch can maintain a group of cancer cells in a dormant state.$^{50}$ Indraccolo et al reported that a short-term perturbation in the tumor microenvironment, in the form of a transient angiogenic burst, could suffice to interrupt tumor dormancy. ${ }^{49}$ Genetic data support the interpretation that minimal residual cancer might be divided into "active" and "dormant" groups, in which an advantageous mutation is acquired shortly before a highly aggressive metastatic clone appears. ${ }^{51}$

At present, there is no definite answer to the question of which model best represents tumor dormancy in breast cancer. Hussein and Komarova hypothesized that indolent breast cancers might fit into the single-cell dormancy model, while more aggressive diseases are linked to the micrometastatic dormancy model. ${ }^{39}$ Indeed, in a series of experiments, Barkan et al demonstrated that more aggressive basal-type cell lines, such as MDA-MB-231, proliferated readily, while estrogen receptor (ER)-positive MCF7 remained in a state of mitotic arrest, potentially linking the dormancy type associated with arrested growth with the less aggressive disease phenotype. ${ }^{52}$

\section{Clinical implications of tumor dormancy}

The phenomenon of clinical cancer dormancy describes a persistent disease without symptoms or signs (chronic disease), unless the balance between tumor cells and their microenvironment is disturbed and a relapse occurs. In breast cancer, $20 \%$ of clinically disease-free patients relapse 7-25 years after mastectomy, and from 10-20 years, the rate of relapse is relatively steady at about $1.5 \%$ per year. ${ }^{26,28,53}$ These recurrences are thought to arise from interruption of the dormant state attributed to DTC.

Recent advances in the field of systemic chemotherapy have yielded improvements in relapse-free and overall survival. Chemotherapy optimally targets highly proliferative cells; however, dormant tumor cells are mostly either slowly proliferating or in a state of arrested growth, explaining the failure of conventional cytotoxic regimes in some breast cancer patients and the need for additional treatment strategies. Further, a large proportion of DTC in breast cancer patients display stem cell-like features, such as ALDH1 positivity or presence of CD44 and absence of CD24. ${ }^{54}$ These stem cell characteristics - eg, immunophenotype, growth characteristics, and low proliferation rate - may determine their resistance to cytostatic therapy. ${ }^{3,6}$ These cells are currently considered to be the persisting, dormant cells and represent a surrogate marker for MRD. New therapeutic options that emerge from understanding tumor cell dormancy include the ability to induce or maintain dormancy and induce apoptosis in residual dormant cells. Studies of tumor dormancy might help determine whether a patient has dormant disease and what type of mechanism is active (single-cell dormancy versus micrometastatic dormancy). Potential therapeutic strategies that arise from dormancy 
studies include: (1) targeting the microenvironment, (2) targeting angiogenesis, (3) targeting signal transduction, and (4) activating the immune system.

\section{Targeting the microenvironment}

Recently, oncologic research has focused increasingly not only on the cancer cell itself but also on complex interactions between malignant cells and their microenvironment. The specific microenvironment determines the extent of cell proliferation, angiogenesis, invasion, and survival. Therefore, systemic treatment should target not only the tumor cell but also the surrounding microenvironment. One such treatment option is bisphosphonates, which are potent inhibitors of osteoclast-mediated bone resorption. There is increasing evidence of their potent anticancer activity in vivo as well as in vitro, supporting a role for these drugs beyond their traditional use in treatment of bone metastases secondary to breast cancer. ${ }^{55,56}$ Several studies confirmed their efficacy in prophylaxis of bone metastasis and their positive impact on survival in selected subgroups of patients. ${ }^{57}$ In vitro bisphosphonates were shown to influence the microenvironment by altered secretion of growth factors and cytokines; inhibit tumor cell adhesion, invasion, and proliferation; and induce apoptosis. ${ }^{58}$ Furthermore, these drugs may act indirectly on cancer cells through microenvironmental changes using immunomodulatory and antiangiogenic effects. Small trials have already demonstrated that dormant DTC in bone marrow of primary breast cancer patients can be eliminated by bisphosphonates. ${ }^{59}$

\section{Targeting angiogenesis}

Once dormant tumor cells leave their quiescent state and their mass reaches a certain size, their growth and survival becomes dependent on the development of a vascular bed and blood vessel recruitment. Angiogenesis is thus a critical feature of tumor growth and its inhibition a potential treatment strategy. Clinical trials on bevacizumab, a monoclonal antibody against VEGF, have shown promising results in metastatic breast cancer patients when this treatment is combined with chemotherapy. ${ }^{60}$ In terms of eliminating dormant tumor cells, antiangiogenic agents might achieve clinically relevant results by preventing angiogenic activation of growth progression (the "angiogenic switch"). Ongoing clinical trials will help to clarify the role of bevacizumab and other angiogenesis inhibitors (eg, small inhibitors of VEGF receptor tyrosine kinases, such as sunitinib) in breast cancer treatment. ${ }^{61}$

\section{Targeting signal transduction}

There is an increasing body of cell-modulating drugs (eg, antibodies or small molecules) directed at specific targets of the cell cycle and of tumorigenesis. The human epidermal growth factor receptor 2 (HER2) is one of the most prominent targets of such approaches. We and others previously reported a discrepancy between cancer cells from the primary tumor and those in secondary sites, such as blood and bone marrow, especially with regard to HER2 and ER status. ${ }^{15,62-65}$ HER2 gene amplification can be acquired during disease progression, even if the primary tumor was HER2negative at the beginning of treatment. ${ }^{66}$ However, patients with HER2-negative tumors but HER2-positive MRD are not eligible for HER2-based treatment. These patients might potentially benefit from such therapy. ${ }^{67}$ Inversely, MRD cells are generally ER-negative and progesterone receptornegative, despite originating from a hormone receptorpositive tumor. ${ }^{15,68}$ This might be relevant to clinicians when selecting patients for targeted or endocrine therapy. In a cohort of 88 patients with ER-positive primary tumors who presented with DTC in their bone marrow, only $14 \%$ had ER-positive DTC. ${ }^{65}$ The loss of ER-positivity in DTC or CTC may explain the failure of endocrine therapy in a subset of ER-positive patients. Therefore, determining the phenotype of MRD is becoming increasingly important, as DTC and CTC are the targets of all adjuvant therapies. While local treatment can adequately deal with the primary tumor and local lymph node metastases, the definitive success of the therapy depends on its ability to eradicate occult tumor cells that persist after primary surgery, before they become clinically evident.

Recent studies suggest that a selected subgroup of patients may benefit from extended adjuvant treatment. Regarding all the validated prognostic factors, monitoring of MRD is the only one available after the primary tumor has been removed. A large pooled analysis demonstrated a strong negative impact of persistent DTC on both disease-free and overall survival. ${ }^{4}$ Recently, Rack et al presented results of an interventional post-adjuvant trastuzumab-based pilot trial. ${ }^{69}$ Ten recurrence-free asymptomatic breast cancer patients with persistent HER2-positive DTC received trastuzumab once every 3 weeks for 12 months. All patients completed chemotherapy at least 6 months prior to entering the study. HER2-targeted therapy eradicated HER2-positive DTC in all patients and significantly reduced the number of DTCpositive patients. Similar results were previously reported by Bozionellou et al. ${ }^{70}$ Trastuzumab effectively targeted 
HER2-positive MRD in 90\%-95\% of initially DTC- or CTC-positive patients.

There are increasing numbers of other highly specific agents targeting signal transduction, including lapatinib (targeting the HER1/2-dependent tyrosine kinase), enzastaurin (targeting protein kinase $\mathrm{C}$ ), lonafarnib (targeting farnesyltransferase), RAD001 (targeting mammalian target of rapamycin), and sunitinib (targeting c-kit, platelet-derived growth factor, and VEGF). The ability to determine the exact nature of MRD cells and to follow changes in their immunophenotype and genotype during disease progression may allow an individual targeted treatment. However, one must bear in mind that elimination of dormant tumor cells may not have a direct impact on survival outcome. Whether patients with persistent MRD benefit from these agents remains to be evaluated in prospective randomized studies.

\section{Activation of immune system}

An interesting treatment strategy may be the use of therapeutic cancer vaccines to stimulate an adaptive immune response that could control or destroy existing cancers. ${ }^{71}$ Various approaches have been developed, including immunization with tumor cells or their antigens and peptides, combined with different adjuvants. The antigens used in breast cancer vaccination strategies can be represented by whole tumor cells (either allogeneic or autologous) or specific tumorassociated antigens, which are delivered as DNA, RNA, protein, or peptide epitopes. ${ }^{72}$ Cancer vaccines are based on the assumption that the patient's immune system can be sensitized to tumor-associated antigens of the patient's own tumor. However, despite decades of investigative efforts, the results are modest. Hypothetically, therapeutic vaccines may be more effective in patients with (dormant) MRD, because the effector-target ratio is more favorable. A limited number of adjuvant trials are in progress.

\section{Role of microenvironment in tumor dormancy}

One unresolved question is whether the tumor cell arriving in the bone marrow is already in a dormant state or becomes dormant because of present or missing factors at the site of its seeding. In the first scenario, the hostile environment outside the tumor stroma might induce dormancy in the tumor cell to allow it to survive the voyage through the bloodstream. Alternatively, seeding a nonpermissive microenvironment might favor the activation of a dormant state. In both situations, reduction of oxygenation and induction of factors such as hypoxia-inducible factor (HIF)-1 $\alpha$ might favor dormancy.
HIF-1 $\alpha$ alpha actually induces the expression of genes associated with neoangiogenesis. ${ }^{73}$ In breast cancer patients, increased expression of HIF-1 $\alpha$ is correlated with dissemination of DTC. ${ }^{74}$ Evidence for this process is still missing, however.

To seed a new environment and to be maintained, a tumor cell must be able to adhere to stromal cells. Such interaction may include $\beta 1$-integrins and epidermal growth factor receptor. ${ }^{75}$ Another important player may be the urokinasetype plasminogen activator receptor (u-PAR). Loss of $\mathrm{u}$-PAR or interruption of the u-PAR pathway activates the p38 mitogen-activated protein kinase stress signaling pathway, which is associated with induction of cell dormancy. ${ }^{76,77}$ The ERK-to-p38 expression ratio seems to regulate the decision to proliferate or to enter a dormant state.

\section{Influence of immune system on tumor dormancy}

Despite some evidence from animal experiments that immune surveillance may be able to control tumor growth, data from patient studies are not convincing that the immune system is significantly involved in maintaining tumor dormancy through surveillance mechanisms. ${ }^{78,79}$ To enable outgrowth, tumor cells are supposed to reduce their immunogenicity by downregulating the expression of antigenic proteins or upregulating ligands, inducing programmed cell death in the immune cells (eg, CD274). A contradicting hypothesis is that the immune system might support the exit of CTC or DTC from the dormant state by cytokines that are released, for example, during inflammation.

\section{Challenges}

The analysis of tumor cell dormancy faces several difficulties. The most important obstacle involves detecting, isolating, and characterizing dormant tumor cells. There is no known specific marker for dormant cells, and current isolation methods based on enrichment of tumor cells using epithelial surface proteins might miss the target population, especially if dormant cells have stem cell capacities.

The next difficulty in characterizing dormant tumor cells is their low frequency. This issue is acerbated because in vitro or in vivo expansion of dormant cells, firstly, is not yet possible and, secondly, might change the phenotype of dormancy and therefore be counterproductive. These obstacles highlight the need for single-cell analysis technologies using micromanipulation in combination with whole-genome or transcriptome amplification steps and miniaturized PCR approaches. The ultimate aim of functional analysis of dormant tumor 
cells in transplantation assays still haunts investigators in this field. Finding the right and most sensitive recipient mouse for xenotransplantation may be a crucial factor. For example, implantation of unselected melanoma cells in Matrigel (a mixture of extracellular matrix components) into highly immunocompromised Nod-SCID IL2Rg ko mice resulted in the outgrowth of tumors from single cells. ${ }^{80}$

\section{How dormant tumor cells are activated}

The decision of a tumor cell either to enter a dormant state or to enter metastatic outgrowth is a very important step. Thus, understanding how dormancy is controlled is of major importance. Some key factors have been identified in recent years: The interaction of tumor cells with fibronectin has been suggested to be an important component of the premetastatic niche and may enable tumor cells to exit dormancy. Another extracellular matrix protein, collagen type I, has been shown to promote the transition from dormancy to metastatic growth. In addition to extracellular matrix components, other factors are thought to regulate dormancy, such as the expression of metastasis suppressor genes, angiostasis, loss of ERK activity, and depletion of cytostatic CD8+ T-cells. ${ }^{76,81-84}$

\section{Conclusion}

Tumor dormancy is an important, albeit poorly understood, stage of cancer progression. The mechanisms underlying tumor cell dormancy during asymptomatic periods of solid cancers are yet to be sufficiently investigated; dormant cancer cells can persist either by completely withdrawing from the cell cycle (mitotic arrest), or by continuing to proliferate at a slow rate that is counterbalanced by cell death. Better understanding of the phenomenon of tumor dormancy could lead to development of appropriate targeted strategies to control this step of the disease and thereby prevent the occasional transformation of dormant cells into metastasis. One treatment option might be to wake up dormant tumor cells, thereby sensitizing them to cytotoxic agents that act on proliferating cells. Alternatively, developing strategies to prevent this awakening could transform breast cancer into a chronic but controllable disease.

\section{Disclosure}

The authors declare that they have no conflicts of interest.

\section{References}

1. Ashworth TR. A case of cancer in which cells similar to those in tumors were seen in the blood after death. Aust Med J. 1869;(14):146-149.
2. Braun S, Vogl FD, Naume B, et al. A pooled analysis of bone marrow micrometastasis in breast cancer. $N$ Engl J Med. 2005;353(8): 793-802.

3. Becker S, Solomayer E, Becker-Pergola G, Wallwiener D, Fehm T. Primary systemic therapy does not eradicate disseminated tumor cells in breast cancer patients. Breast Cancer Res Treat. 2007;106(2):239-243. Epub January 27, 2007.

4. Janni W, Rack B, Schindlbeck C, et al. The persistence of isolated tumor cells in bone marrow from patients with breast carcinoma predicts an increased risk for recurrence. Cancer. 2005;103(5):884-891.

5. Cristofanilli M, Budd GT, Ellis MJ, et al. Circulating tumor cells, disease progression, and survival in metastatic breast cancer. $N$ Engl $J$ Med. 2004;351(8):781-791.

6. Rack BK, Schindlbeck C, Andergassen U, et al. Use of circulating tumor cells (CTC) in peripheral blood of breast cancer patients before and after adjuvant chemotherapy to predict risk for relapse: The SUCCESS trial. ASCO Annual Meeting 2010 [abstract]. J Clin Oncol. 2010;28:Suppl 15s:1003.

7. Liotta LA, Kleinerman J, Saidel GM. Quantitative relationships of intravascular tumor cells, tumor vessels, and pulmonary metastases following tumor implantation. Cancer Res. 1974;34(5):997-1004.

8. Butler TP, Gullino PM. Quantitation of cell shedding into efferent blood of mammary adenocarcinoma. Cancer Res. 1975;35(3):512-516.

9. Mehes G, Witt A, Kubista E, Ambros PF. Circulating breast cancer cells are frequently apoptotic. Am J Pathol. 2001;159(1):17-20.

10. Larson CJ, Moreno JG, Pienta KJ, et al. Apoptosis of circulating tumor cells in prostate cancer patients. Cytometry A. 2004;62(1):46-53.

11. Fidler IJ. Metastasis: Quantitative analysis of distribution and fate of tumor emboli labeled with 125 I-5-Iodo-2'-desoxyuridine. J Natl Cancer Inst. 1970;45:773-782.

12. Frisch SM, Screaton RA. Anoikis mechanisms. Curr Opin Cell Biol. 2001;13(5):555-562.

13. Liotta LA, Saidel GM, Kleinerman J. Stochastic model of metastases formation. Biometrics. 1976;32(3):535-550.

14. Liotta LA, Saidel MG, Kleinerman J. The significance of hematogenous tumor cell clumps in the metastatic process. Cancer Res. 1976;36(3):889-894.

15. Banys M, Krawczyk N, Becker S, et al. The influence of removal of primary tumor on incidence and phenotype of circulating tumor cells in primary breast cancer. Breast Cancer Res Treat. 2012;132(1):121-129. Epub May 12, 2011.

16. Krag DN, Ashikaga T, Moss TJ, et al. Breast cancer cells in the blood: a pilot study. Breast J. 1999;5(6):354-358.

17. Luzzi KJ, Macdonald IC, Schmidt EE, et al. Multistep nature of metastatic inefficiency: dormancy of solitary cells after successful extravasation and limited survival of early micrometastases. $\mathrm{Am} \mathrm{J}$ Pathol. 1998;153(3):865-873.

18. Cameron MD, Schmidt EE, Kerkvliet N, et al. Temporal progression of metastasis in lung: cell survival, dormancy, and location dependence of metastatic inefficiency. Cancer Res. 2000;60(9):2541-2546.

19. Kienast Y, Von Baumgarten L, Fuhrmann M, et al. Real-time imaging reveals the single steps of brain metastasis formation. Nat Med. 2010;16(1):116-122.

20. Sleeman JP, Nazarenko I, Thiele W. Do all roads lead to Rome? Routes to metastasis development. Int J Cancer. 2011;128(11):2511-2526.

21. Paget S. Distribution of secondary growths in cancer of the breast. Lancet. 1889;1:571.

22. Psaila B, Lyden D. The metastatic niche: adapting the foreign soil. Nat Rev Cancer. 2009;9(4):285-293.

23. Kaplan RN, Riba RD, Zacharoulis S, et al. VEGFR1-positive haematopoietic bone marrow progenitors initiate the pre-metastatic niche. Nature. 2005;438(7069):820-827.

24. Erler JT, Weaver VM. Three-dimensional context regulation of metastasis. Clin Exp Metastasis. 2009;26(1):35-49.

25. Kaplan RN, Psaila B, Lyden D. Bone marrow cells in the 'premetastatic niche': within bone and beyond. Cancer Metastasis Rev. 2006;25(4):521-529. 
26. Demicheli R, Abbattista A, Miceli R, Valagussa P, Bonadonna G. Time distribution of the recurrence risk for breast cancer patients undergoing mastectomy: further support about the concept of tumor dormancy. Breast Cancer Res Treat. 1996;41(2):177-185.

27. Pocock SJ, Gore SM, Kerr GR. Long term survival analysis: the curability of breast cancer. Stat Med. 1982;1(2):93-104.

28. Karrison TG, Ferguson DJ, Meier P. Dormancy of mammary carcinoma after mastectomy. J Natl Cancer Inst. 1999;91(1):80-85.

29. Willis RA. The Spread of Tumors in the Human Body. London: J\&A Churchill; 1934.

30. Meng S, Tripathy D, Frenkel EP, et al. Circulating tumor cells in patients with breast cancer dormancy. Clin Cancer Res. 2004;10(24): 8152-8162.

31. Holmgren L, O'Reilly MS, Folkman J. Dormancy of micrometastases: balanced proliferation and apoptosis in the presence of angiogenesis suppression. Nat Med. 1995;1(2):149-153.

32. Morgan TM, Lange PH, Porter MP, et al. Disseminated tumor cells in prostate cancer patients after radical prostatectomy and without evidence of disease predicts biochemical recurrence. Clin Cancer Res. 2009;15(2):677-683.

33. Goodison S, Kawai K, Hihara J, et al. Prolonged dormancy and sitespecific growth potential of cancer cells spontaneously disseminated from nonmetastatic breast tumors as revealed by labeling with green fluorescent protein. Clin Cancer Res. 2003;9(10 Pt 1):3808-3814.

34. Wikman H, Vessella R, Pantel K. Cancer micrometastasis and tumour dormancy. APMIS. 2008;116(7-8):754-770.

35. Becker S, Becker-Pergola G, Wallwiener D, Solomayer EF, Fehm T. Detection of cytokeratin-positive cells in the bone marrow of breast cancer patients undergoing adjuvant therapy. Breast Cancer Res Treat. 2006;97(1):91-96.

36. Frisch SM, Francis H. Disruption of epithelial cell-matrix interactions induces apoptosis. J Cell Biol. 1994;124(4):619-626.

37. Fehm T, Mueller V, Marches R, et al. Tumor cell dormancy: implications for the biology and treatment of breast cancer. APMIS. 2008;116(7-8):742-753.

38. Aguirre-Ghiso JA. Models, mechanisms and clinical evidence for cancer dormancy. Nat Rev Cancer. 2007;7(11):834-846.

39. Hussein O, Komarova SV. Breast cancer at bone metastatic sites: recent discoveries and treatment targets. J Cell Commun Signal. 2001; $5(2): 85-99$.

40. Townson JL, Chambers AF. Dormancy of solitary metastatic cells. Cell Cycle. 2006;5(16):1744-1750.

41. White DE, Rayment JH, Muller WJ. Addressing the role of cell adhesion in tumor cell dormancy. Cell Cycle. 2006;5(16):1756-1759.

42. Ranganathan AC, Adam AP, Aguirre-Ghiso JA. Opposing roles of mitogenic and stress signaling pathways in the induction of cancer dormancy. Cell Cycle. 2006;5(16):1799-1807.

43. Aguirre Ghiso JA, Kovalski K, Ossowski L. Tumor dormancy induced by downregulation of urokinase receptor in human carcinoma involves integrin and MAPK signaling. $J$ Cell Biol. 1999;147(1):89-104.

44. Naumov GN, Macdonald IC, Weinmeister PM, et al. Persistence of solitary mammary carcinoma cells in a secondary site: a possible contributor to dormancy. Cancer Res. 2002;62(7):2162-2168.

45. Fisher JL, Thomas-Mudge RJ, Elliott J, et al. Osteoprotegerin overexpression by breast cancer cells enhances orthotopic and osseous tumor growth and contrasts with that delivered therapeutically. Cancer Res. 2006;66(7):3620-3628.

46. Holen I, Cross SS, Neville-Webbe HL, et al. Osteoprotegerin (OPG) expression by breast cancer cells in vitro and breast tumours in vivo - a role in tumour cell survival? Breast Cancer Res Treat. 2005;92(3):207-215.

47. Neville-Webbe HL, Cross NA, Eaton CL, et al. Osteoprotegerin (OPG) produced by bone marrow stromal cells protects breast cancer cells from TRAIL-induced apoptosis. Breast Cancer Res Treat. 2004;86(3):269-279.

48. Zhang XH, Wang Q, Gerald W, et al. Latent bone metastasis in breast cancer tied to Src-dependent survival signals. Cancer Cell. 2009; 16(1):67-78.
49. Indraccolo S, Stievano L, Minuzzo S, et al. Interruption of tumor dormancy by a transient angiogenic burst within the tumor microenvironment. Proc Natl Acad Sci U S A. 2006;103(11):4216-4221.

50. Naumov GN, Bender E, Zurakowski D, et al. A model of human tumor dormancy: an angiogenic switch from the nonangiogenic phenotype. $J$ Natl Cancer Inst. 2006;98(5):316-325.

51. Klein CA, Blankenstein TJ, Schmidt-Kittler O, et al. Genetic heterogeneity of single disseminated tumour cells in minimal residual cancer. Lancet. 2002;360(9334):683-689.

52. Barkan D, Kleinman H, Simmons JL, et al. Inhibition of metastatic outgrowth from single dormant tumor cells by targeting the cytoskeleton. Cancer Res. 2008;68(15):6241-6250.

53. Uhr JW, Pantel K. Controversies in clinical cancer dormancy. Proc Natl Acad Sci U S A. 2011;108(30):12396-12400.

54. Balic M, Lin H, Young L, et al. Most early disseminated cancer cells detected in bone marrow of breast cancer patients have a putative breast cancer stem cell phenotype. Clin Cancer Res. 2006;12(19):5615-5621.

55. Holen I, Coleman RE. Anti-tumour activity of bisphosphonates in preclinical models of breast cancer. Breast Cancer Res. 2010;12(6):214.

56. Fournier PG, Stresing V, Ebetino FH, Clezardin P. How do bisphosphonates inhibit bone metastasis in vivo? Neoplasia. 2010;12(7): 571-578.

57. Diel IJ, Jaschke A, Solomayer EF, et al. Adjuvant oral clodronate improves the overall survival of primary breast cancer patients with micrometastases to the bone marrow: a long-term follow-up. Ann Oncol. 2008;19(12):2007-2011.

58. Clezardin P, Ebetino FH, Fournier PG. Bisphosphonates and cancerinduced bone disease: beyond their antiresorptive activity. Cancer Res. 2005;65(12):4971-4974.

59. Solomayer EF, Gebauer G, Hirnle P, et al. Influence of zoledronic acid on disseminated tumor cells in primary breast cancer patients. Ann Oncol. Epub March 1, 2012.

60. Robert NJ, Dieras V, Glaspy J, et al. RIBBON-1: randomized, doubleblind, placebo-controlled, phase III trial of chemotherapy with or without bevacizumab for first-line treatment of human epidermal growth factor receptor 2-negative, locally recurrent or metastatic breast cancer. J Clin Oncol. 2011;29(10):1252-1260.

61. Mackey JR, Kerbel RS, Gelmon KA, et al. Controlling angiogenesis in breast cancer: A systematic review of anti-angiogenic trials. Cancer Treat Rev. 2012;38(6):673-688.

62. Solomayer EF, Becker S, Pergola-Becker G, et al. Comparison of HER2 status between primary tumor and disseminated tumor cells in primary breast cancer patients. Breast Cancer Res Treat. 2006;98(2):179-184.

63. Krawczyk N, Banys M, Neubauer H, et al. HER2 status on persistent disseminated tumor cells after adjuvant therapy may differ from initial HER2 status on primary tumor. Anticancer Res. 2009;29(10):4019-4024.

64. Fehm T, Hoffmann O, Aktas B, et al. Detection and characterization of circulating tumor cells in blood of primary breast cancer patients by RT-PCR and comparison to status of bone marrow disseminated cells. Breast Cancer Res. 2009;11(4):R59.

65. Fehm T, Krawczyk N, Solomayer EF, et al. ERalpha-status of disseminated tumour cells in bone marrow of primary breast cancer patients. Breast Cancer Res. 2008;10(5):R76.

66. Meng S, Tripathy D, Shete S, et al. HER-2 gene amplification can be acquired as breast cancer progresses. Proc Natl Acad Sci U S A. 2004;101(25):9393-9398.

67. Jückstock J, Rack B, Schindlbeck C, et al. Treatment with trastuzumab in recurrence free patients with early breast cancer and persistent disseminated tumor cells (DTC) in bone marrow. Proceedings of the San Antonio Breast Cancer Symposium December 10-14, 2008; San Antonio (TX), USA.

68. Aktas B, Muller V, Tewes M, et al. Comparison of estrogen and progesterone receptor status of circulating tumor cells and the primary tumor in metastatic breast cancer patients. Gynecol Oncol. 2011;122(2):356-360. Epub May 24, 2011. 
69. Rack B, Juckstock J, Gunthner-Biller M, et al. Trastuzumab clears HER2/neu-positive isolated tumor cells from bone marrow in primary breast cancer patients. Arch Gynecol Obstet. 2012;285(2):485-492. Epub June 30, 2011.

70. Bozionellou V, Mavroudis D, Perraki M, et al. Trastuzumab administration can effectively target chemotherapy-resistant cytokeratin-19 messenger RNA-positive tumor cells in the peripheral blood and bone marrow of patients with breast cancer. Clin Cancer Res. 2004;10(24):8185-8194.

71. Curigliano G, Spitaleri G, Pietri E, et al. Breast cancer vaccines: a clinical reality or fairy tale? Ann Oncol. 2006;17(5):750-762.

72. Schlom J. Therapeutic cancer vaccines: current status and moving forward. J Natl Cancer Inst. 2012;104(8):599-613.

73. Semenza GL. Targeting HIF-1 for cancer therapy. Nat Rev Cancer 2003;3(10):721-732.

74. Woelfle U, Cloos J, Sauter G, et al. Molecular signature associated with bone marrow micrometastasis in human breast cancer. Cancer Res. 2003;63(18):5679-5684.

75. Weaver VM, Petersen OW, Wang F, et al. Reversion of the malignant phenotype of human breast cells in three-dimensional culture and in vivo by integrin blocking antibodies. J Cell Biol. 1997;137(1):231-245.

76. Aguirre-Ghiso JA, Estrada Y, Liu D, Ossowski L. ERK(MAPK) activity as a determinant of tumor growth and dormancy; regulation by p38(SAPK). Cancer Res. 2003;63(7):1684-1695.

77. Ranganathan AC, Zhang L, Adam AP, Aguirre-Ghiso JA. Functional coupling of p38-induced up-regulation of BiP and activation of RNA-dependent protein kinase-like endoplasmic reticulum kinase to drug resistance of dormant carcinoma cells. Cancer Res. 2006;66(3): $1702-1711$.
78. Matsuzawa A, Takeda Y, Narita M, Ozawa H. Survival of leukemic cells in a dormant state following cyclophosphamide-induced cure of strongly immunogenic mouse leukemia (DL811). Int J Cancer. 1991; 49(2):303-309.

79. Rabinovsky R, Uhr JW, Vitetta ES, Yefenof E. Cancer dormancy: lessons from a B cell lymphoma and adenocarcinoma of the prostate. Adv Cancer Res. 2007;97:189-202.

80. Quintana E, Shackleton M, Sabel MS, Fullen DR, Johnson TM, Morrison SJ. Efficient tumour formation by single human melanoma cells. Nature. 2008;456(7222):593-598.

81. Nash KT, Phadke PA, Navenot JM, et al. Requirement of KISS1 secretion for multiple organ metastasis suppression and maintenance of tumor dormancy. J Natl Cancer Inst. 2007;99(4):309-321.

82. Horak CE, Lee JH, Marshall JC, Shreeve SM, Steeg PS. The role of metastasis suppressor genes in metastatic dormancy. APMIS. 2008;116(7-8):586-601.

83. Barkan D, Green JE, Chambers AF. Extracellular matrix: a gatekeeper in the transition from dormancy to metastatic growth. Eur J Cancer. 2010;46(7):1181-1188.

84. Eyles J, Puaux AL, Wang X, et al. Tumor cells disseminate early, but immunosurveillance limits metastatic outgrowth, in a mouse model of melanoma. J Clin Invest. 2010;120(6):2030-2039.
Breast Cancer: Targets and Therapy

\section{Publish your work in this journal}

Breast Cancer: Targets and Therapy is an international, peerreviewed open access journal focusing on breast cancer research, identification of therapeutic targets and the optimal use of preventative and integrated treatment interventions to achieve improved outcomes, enhanced survival and quality of life for the cancer patient.

\section{Dovepress}

View the full aims and scopes of this journal here. The manuscript management system is completely online and includes a very quick and fair peer-review system, which is all easy to use. Visit http:// www.dovepress.com/testimonials.php to read real quotes from published authors. 